(2) Open Access Full Text Article

REVIEW

\title{
Amatuximab and novel agents targeting mesothelin for solid tumors
}

This article was published in the following Dove Press journal:

OncoTargets and Therapy

8 November 2017

Number of times this article has been viewed

Paolo Baldo
Sara Cecco

Pharmacy Unit, Directorate Department, CRO Aviano-IRCCS National Cancer Institute, Aviano, Italy
Abstract: Mesothelin (MSLN) is considered a promising target for cancer therapy. Originally extracted in 1992 after the immunization of mice with a human ovarian cancer (OC) cell line and cloned in 1996, MSLN seems to be involved in cell adhesion and metastasis. MSLN is prevalent in mesothelia tissues but is expressed in several human cancers, such as OC, pancreatic cancer, mesothelioma, and lung cancer. Amatuximab (MORAb-009) is a mouse-human chimeric monoclonal antibody with a selective affinity for MSLN. The principal mechanism of action comprises inhibition of binding of MSLN with the antigen CA125/MUC16. The highest phase of development is actually a Phase II trial (MORAb-009-201, Europe). In this review, we describe the mechanism of action of amatuximab and other MSLN-targeting novel drugs, along with a discussion about the expected efficacy, safety, and toxicity of this promising group of agents and implications for future research and clinical practice.

Keywords: amatuximab, monoclonal antibody, mesothelin, antigen, mesothelioma, target therapy

\section{Plain language summary}

Mesothelin (MSLN) is a glycoprotein, detectable on the surface of mesothelial cells. Although its biological function in normal cells is completely clarified, it is overexpressed in many types of cancer, and in cancerous cells, it may be involved in the promotion of cell proliferation, adhesion and migration, chemotherapy resistance, and inhibition of apoptosis. MSLN seems to be an interesting target in diagnosing and treating several solid tumors, in particular mesothelioma, which, for the aggressive nature of the disease, still represents one of the concrete challenges for modern oncology. In this review, we comprehensively describe MSLN as a potential target for cancer therapy, along with a presentation of profiles of the new agents under investigation for mesothelioma and other solid tumors. A list of ongoing clinical trials is provided.

\section{Introduction}

Mesothelin (MSLN) is considered an interesting and promising target for cancer research and therapy. It was initially identified as the cell surface antigen CAK1 by Chang et al in 1992: ${ }^{1}$ then, it was characterized and cloned as a $40-\mathrm{kDa}$ glycoprotein detected on the surface of normal mesothelial cells. ${ }^{2}$ It is overexpressed by cancer cells in mesothelioma, ovarian cancer (OC), pancreatic cancer (PC), and other solid tumors. Relatively recent research detected high MSLN expression in acute myeloid leukemia ${ }^{3}$ and in cholangiocarcinoma. ${ }^{4}$ The name "mesothelin" was assigned to highlight the presence of the protein in normal mesothelial cells, including pleura, pericardium, fallopian tubes, trachea, and cornea.

The precursor, which is a 71-kDa protein that is encoded by a 2,138-bp-long cDNA and contains 628 amino acids, is then cleaved into two products, a $\sim 31-\mathrm{kDa}$ N-terminal
Correspondence: Paolo Baldo

Pharmacy Unit, Directorate Department, CRO Aviano-IRCCS National Cancer Institute, Via F. Gallini, 2, Aviano (PN) Italy

Tel +39043465922 I

Fax +390434659743

Email pbaldo@cro.it
OncoTargets and Therapy 2017:10 5337-5353

(c) (1) (2) ๑ 2017 Baldo and Cecco. This work is pulished and licensed by Dove Medical Press Limited. The full terms of this license are available at https:/www.dovepress.com/terms.php cc) hereby accept the Terms. Non-commercial uses of the work are permitted without any further permisision from Dove Medical Press Limited, provided the work is properly attributed. For permission for commercial use of this work, please see paragraphs 4.2 and 5 of our Terms (htpps://www.dovepress. com/terms.php). 
region, called megakaryocyte potentiating factor (MPF), and the $\sim 40-\mathrm{kDa}$ mesothelin protein, which is the main form represented on the cell surface. MSLN is commonly a membrane-bound, glycosylphosphatidylinositol (GPI)-linked protein, but it is also detectable in a soluble form (soluble MSLN protein [SMP]), which is shed from cancer cells. ${ }^{5}$ Patterns of MSLN expression in some types of cancer cells are characterized by using immunohistochemistry, ${ }^{6}$ exploiting the SAGE database, ${ }^{7}$ and using the antibody mAb5B2. ${ }^{8}$ Detection of MSLN in serum is a useful marker in cancer diagnostic procedures. ${ }^{9}$

The biological function of MSLN in normal cells is not completely clarified. It is likely to be involved in cell adhesion, differentiation, and signal transduction, ${ }^{10}$ and in cancerous cells, it may be involved in the promotion of proliferation, cell migration and spread, chemotherapy resistance, and inhibition of apoptosis. The capability of MSLN to bind to the cancer antigen CA-125, also called mucin 16 (or MUC16), suggests that MSLN is involved in cell adhesion and is an important target for innovative anticancer agent. ${ }^{11-13}$ The overexpression of MSLN activates multiple intracellular pathways, including nuclear factor-kappaB (NFKB), MAPK, and PI3K pathways, with the consequent promotion of cell proliferation, migration, and metastasis to distal sites and the inhibition of apoptosis. ${ }^{14,15}$ Importantly, in recent years, the activation and stimulation of immune reactions using engineered $\mathrm{T}$-cells with chimeric antigen receptors (CARs) allowed the characterization of antigens, including MSLN, overexpressed in solid tumors and in several B-cell malignancies, including acute lymphoblastic leukemia, chronic lymphocytic leukemia, and non-Hodgkin lymphoma. ${ }^{16,17}$

After the cleavage, MPF acts as a cytokine that stimulates colony formation in bone marrow megakaryocytes. MSLN is a GPI-anchored cell-surface protein that performs cell adhesion modulating activities.

\section{MSLN as a therapeutic target in mesothelioma}

Mesothelioma is a rare cancer deriving from the mesothelium, which lines the pleura and other serous cavities (such as the peritoneum, pericardium, and tunica vaginalis testis), is the main form of cancer in these structures, and is often characterized by a poor prognosis. Mesothelioma is described in the benign or malign subtypes. Surgery is the choice option for the benign form, but in case of malign transformation, the overall estimated survival is $24-36$ months. ${ }^{18}$ The malignant form (malignant mesothelioma $[\mathrm{MM}]$ ) has an epithelial morphology, or a fibrous one, also called sarcomatoid, or a combination of the two. MSLN is overexpressed in up to $95 \%$ of patients with the epithelioid form. In contrast, in the sarcomatoid form (10\%-15\% of all mesotheliomas), there is no overexpression of MSLN. ${ }^{19,20}$

The crude annual incidence of MM in Europe is 2 new cases per 100,000, while the prevalence is 3.5 cases per $100,000 .{ }^{21}$ According to data from the American Cancer Society, in the United States, the annual incidence is estimated to be $\sim 3,000$ new cases per year. ${ }^{22,23}$ The global incidence trend indicates 36,925 incident cases in 2015 versus 26,376 in 2005 , with an overall change of $40 \%$ due to different factors (such as population growth, age trends, and change in incidence). ${ }^{24}$

The most important risk factor for the development of $\mathrm{MM}$ is inhalation of asbestos, which induces oncogenesis via the activation of the NF- $\mathrm{BB}$-dependent pathway. ${ }^{25}$ Asbestos, whose principal components are two types of fibers, serpentine and amphibole, was largely used until 1980s-1990s, for its excellent acoustic and thermal insulation properties and its mechanical strength. A very long latency period - up to 25-40 years ${ }^{26}$ - can elapse before the development of this tumor. Moreover, developed countries are gradually promoting laws to restrict the use of asbestos, which means that some countries expect that the peak incidence has already been reached. Other known risk factors include therapeutic radiation ${ }^{27}$ and genetic factors. ${ }^{28}$

Diagnostic procedures include imaging, cytology, and immunohistochemistry, but, to date, no technique is considered individually certain for the purposes of early diagnosis. ${ }^{29}$ Surgery is applied with a prognostic/palliative intent, while standard chemotherapy is based on a treatment with cisplatin combined with an antifolate (pemetrexed or raltitrexed). New therapeutic approaches under evaluation include angiogenesis inhibitors, ${ }^{30}$ mTOR inhibitors, ${ }^{31}$ and histone deacetylase inhibitors. ${ }^{32}$ Given the overexpression of MSLN in $>80 \%$ of total MM cases, new agents targeting MSLN under evaluation in clinical trials are considered a very promising field for research and therapy.

\section{MSLN as a therapeutic target in other solid tumors}

MSLN seems to be overexpressed in $\sim 30 \%$ of all cancers. ${ }^{33}$ MSLN expression in different types of solid tumors is described comprehensively by Hassan et $\mathrm{al}^{34}$ (see also The Human Protein Atlas). ${ }^{35}$

\section{Pancreatic cancer}

PC was investigated for the expression of MSLN by Argani et al, ${ }^{36}$ Hassan et al, ${ }^{37}$ and Zervos et al,${ }^{38}$ showing a high 
expression of MSLN for most of the pancreatic adenocarcinomas but not in normal pancreatic cells. At the same time, their studies revealed the presence of MSLN in other adenocarcinomas of the biliary tract. Recent data confirm the hypothesis that new immunotoxins actually investigated in clinical trials, such as LMB-100 (previously named RG7787), might have synergistic anticancer effects when used in combination with taxanes or other standard chemotherapy. ${ }^{39}$

\section{Ovarian cancer}

OC expresses, especially in the non-mucinous variant of cancer cells, high levels of MSLN. Hanaoka et $\mathrm{al}^{40}$ showed that $68.8 \%$ of OCs and $24.2 \%$ of borderline-type tumors express high MSLN levels, with implications for a shorter progression-free survival (PFS) and overall survival (OS). An analysis of MSLN expression is currently being performed by using immunohistochemistry and imaging techniques (immunoPET) with positron-emitting isotopes $\left({ }^{89} \mathrm{Zr}\right.$-labeled $\mathrm{mAbs}$ and ${ }^{64} \mathrm{Cu}$-labeled $\mathrm{mAbs}$ ) to evaluate the tumor uptake of innovative antibody-drug conjugate (ADC) immunotherapeutic agents. ${ }^{41,42}$ The resulting data will be helpful to predict the potential utility and efficacy of new immunoconjugates in the therapy of these types of cancer. ${ }^{43}$

\section{Breast cancer}

Currently, there is a plethora (451) of studies regarding targeted therapies for breast cancer (BC) (as reported in ClinicalTrials.gov trials register) ${ }^{44}$ However, only 5 studies correlated with MSLN as the main biomarker (for reference see Table 1). In treating BC, MSLN, as a target, may be particularly promising for triple-negative breast cancers (TNBC), one of the most aggressive forms of BC. Li et al investigated MSLN as a prognostic BC biomarker, whose expression is highly enriched especially in African-American women. ${ }^{45}$ These results are consistent with data published by Bayoglu et $\mathrm{al}^{46}$ and Parinyanitikul et $\mathrm{al},{ }^{47}$ who, respectively, reported a prevalence of $42.3 \%$ and $34 \%$ of patients expressing MSLN in TNBC. However, they suggested that MSLN overexpression may not have a prognostic value and does not correlate with the survival outcomes in patients with TNBC. Future work is needed to evaluate the potential of MSLN-targeted therapy in the treatment of BC.

\section{Lung cancer}

Ordonez, Miettinen and Sarlomo-Rikala performed immunohistochemistry studies using the MSLN-specific antibody $5 \mathrm{~B} 2$ and showed that $38 \%-40 \%$ of lung adenocarcinomas stain positively for MSLN. ${ }^{48,49}$ In another study, the presence of the MSLN precursor was detected in $82 \%$ of lung adenocarcinoma, and its mature form was detected in 55\% of patients. ${ }^{50}$

\section{Head and neck cancers}

The expression of MSLN in the human leptomeninges and meningiomas is not completely studied and understood. There are similarities in the structure and functions of the pleura and leptomeninges, and this suggests that MSLN might play a role in the meningeal function and could be expressed in meningiomas. ${ }^{51}$ Future research is necessary to better understand the possible role of MSLN as a target for therapy of gliomas, meningiomas, and/or other head and neck cancers. The overexpression of MSLN was also determined by immunohistochemistry in thymic carcinomas, suggesting that MSLN is a potential important target for this type of cancer..$^{52,53}$

\section{Gastric cancer}

Tomoaki et al investigated the expression and extracellular secretion of MSLN in human gastric cancer cell lines and found lower expression levels in the human gastric cancer compared to those noted in human mesothelioma cells, ${ }^{54}$ and the levels were not specific to gastric cancer. Recently, Han et $\mathrm{al}^{55}$ found that $25.6 \%$ of a cohort of 117 patients with gastric carcinoma showed high levels of MSLN expression, which was associated with a poor prognosis. They concluded that MSLN-targeted therapies merit further research in patients with gastric carcinomas.

\section{MSLN targeting: amatuximab (MORAb-009)}

Amatuximab (alternative names: MORAb-009, anti-MSLN monoclonal antibody [MAb]) is a chimeric, humanized IgG1/k MAb that targets the cell surface MSLN. The precursor of MORAb-009 was isolated by Chowdhury et al in $1998^{56}$ from a mouse splenic mRNA and was then optimized by fusing the gene encoding MSLN Fv (SS1 scFv) with human IgG1 and kappa regions. ${ }^{57}$ Amatuximab consists in $83 \%$ of human and $17 \%$ of murine sequences, and it is comprised of 2 identical heavy and 2 identical light chains connected by disulfide bonds. The substance can potentially reduce tumor growth by inhibiting MSLN binding to the extracellular substrate and also by antibody-dependent cellular cytotoxicity (ADCC). Amatuximab is not yet commercially available, and the highest development phase is Phase II. It is actually investigated in trials for the treatment of pleural mesothelioma and PC in the USA, Europe, Canada, and South America. Today, the primary focus is to evaluate its efficacy against mesotheliomas. 


\section{Pharmacology}

Pharmacodynamics

After the characterization of amatuximab, Hassan et $\mathrm{al}^{57}$ performed preclinical studies to investigate the ability of amatuximab to target the MSLN protein expressed in some human cancer cells, to internalize in cancer cells after binding MSLN and to exert ADCC.

Results from the preclinical studies indicate a potential relevant interaction between amatuximab and tumorigenic cells/tissues overexpressing MSLN, and specifically:

- In immunohistochemistry studies, MSLN-positive tumor cells show strong cell surface staining, as reported by investigational medicinal product (IMP) dossier and by independent studies; $;^{1,58}$

- In antibody-dependent cytotoxicity studies, amatuximab enhances ADCC in MSLN-positive cancer cell lines, but not at comparable levels in MSLN-negative cell lines; $; 9,60$

- In standard in vivo murine xenograft studies, Hassan et $\mathrm{al}^{57}$ and Morphotek Inc. investigated the potential effects of amatuximab as a single agent or in combination with gemcitabine and rituximab. Amatuximab alone resulted in a significant reduction of tumor dimension in the intervention group (amatuximab-treated) compared to the control group (29.9\% difference). Rituximab had no measurable effects, while some synergy with gemcitabine was detected, as an additive effect;

- In adhesion blocking assays, amatuximab inhibited the interaction of MSLN-expressing cells with MUC16expressing cells, a factor considered of great importance for reducing cell adhesion, migration patterns, and finally metastasis. ${ }^{61}$

\section{Pharmacokinetics (PK)}

Amatuximab, in actual clinical trials, is administered intravenously at the identified maximum tolerated dose (MTD) of $200 \mathrm{mg} / \mathrm{m}^{2}$. The main available data about MORAb009 PK are described by Hassan et al, ${ }^{62}$ Gupta et al, ${ }^{63}$ and Fujisaka et al. ${ }^{64}$ The population PK analysis of the data collected from previous Phase I and Phase II studies in PC or malignant pleural mesothelioma (MPM) describes a two-compartment model, incorporating parallel linear and nonlinear (Michaelis-Menten) pathways for elimination from the central compartment. The nonlinear elimination is related to the interaction with the variable cell internalization of the antigen-antibody complex Ab-MSLN. In summary, PK studies estimate that a dose of $5 \mathrm{mg} / \mathrm{kg}$, administered weekly, achieves a steady-state $C_{\min }$ of $83.1 \mathrm{mg} / \mathrm{mL}$ and is considered a balanced reference dose for efficacy and safety in $\sim 80 \%$ of subjects. The serum concentration-time profile of amatuximab suggests that after 5 weeks of weekly dosing, $89 \%$ of the steady-state concentration level is reached. Factors, including weight, age, gender, and race, seem not to influence the pharmacological effects of amatuximab. Combination schedules with other chemotherapy drugs, for example, cisplatin and pemetrexed therapies, show synergic potentiation and reach a higher steady state $C_{\min }$. Other models to investigate the distribution of amatuximab in the body and the patterns of penetration in cancer formations are based on imaging techniques using SPECT. ${ }^{65}$

\section{Safety and expected toxicity}

Amatuximab is actually under investigation in several international trials. For this reason, the safety profile is implemented day after day following the adverse events (AEs) clinical reporting and applying pharmacovigilance signal detection. Phase I and Phase II studies investigated the safety and tolerability of amatuximab; although indicating a discrete tolerability, they showed that $54.2 \%{ }^{62}$ to $76.5 \%{ }^{64}$ of patients experienced AEs that were considered to be associated with the amatuximab treatment. Among a total of 41 patients in two studies (24+17, respectively), 10\%-29.4\% experienced AEs (including cytokine release syndrome, hot flushes, pyrexia, arthralgia, and nausea) that were potentially related to immune-mediated mechanism, which is relevant to the fact that amatuximab is a MAb. Other common AEs include fatigue (the most frequent), liver function elevation (AST, ALT, ALKP, and serum bilirubin), vomiting, decrease in appetite and weight, headache, hypotension, dizziness, and allergic reactions. It is reported that only one patient died of interstitial lung disease (ILD), and the cause was related to an $\mathrm{AE}$ to the amatuximab treatment.

\section{Genotoxicity/teratogenity/pregnancy: available data}

To date, no genotoxicity or teratogenicity or pregnancy studies have been planned and conducted for amatuximab. Amatuximab belongs to the pharmacological class of monoclonal antibodies and is expected not to be genotoxic.

\section{Amatuximab in clinical studies}

Amatuximab is investigated in trials for the treatment of pleural mesothelioma and PC in USA, Europe, Canada, and South America. The primary intention of researchers is the evaluation of its efficacy against mesotheliomas. An "investigational new drug application" was launched by Morphotek for amatuximab in 2006. 
In this paper, we refer to amatuximab and other antiMSLN agent studies citing the Clinical Trials Identifier (NCT number) in Medline (www.ClinicalTrials.gov). ${ }^{44}$ A summary of the clinical trials of amatuximab for MSLN-expressing tumors currently listed on ClinicalTrials.gov is presented in Table 2.

Initially, a Phase I clinical trial (NCT00325494) was planned, ${ }^{66}$ recruiting 24 subjects with PC or mesothelioma or non-small-cell lung cancer (NSLC) or OC. The primary outcome measures included the evaluation of safety and tolerability of amatuximab, the frequency and severity of the AEs and of the serious adverse events (SAEs), laboratory parameters, and cardiovascular examinations. The dose range that was investigated was between 12.5 and $400 \mathrm{mg} / \mathrm{m}^{2}$. The MTD was set to $200 \mathrm{mg} / \mathrm{m}^{2}$. A similar Phase I clinical trial (NCT01018784) ${ }^{67}$ was performed in 17 Japanese patients. The aims of the study were to determine dose-limiting toxicity (DLT) and MTD. In this trial, Fujisaka et al ${ }^{64}$ reached similar conclusions, and the weekly dose was determined to be $200 \mathrm{mg} / \mathrm{m}^{2}$. Taking into account an acceptable safety profile and the potential of obtaining clinical benefit, a subsequent Phase II, multicentric, single-arm, open-label trial (NCT00738582) ${ }^{68}$ recruited 89 patients presenting unresectable MPM, naïve to chemotherapy. Amatuximab was administered in association with standard chemotherapy regimens, with the primary objective to improve PFS. The secondary outcome measures were the OS, overall response (OR), and evaluation of the safety profile of amatuximab. The PFS was not improved in the treatment group compared to the controls. However, the combined therapy of amatuximab plus pemetrexed/cisplatin gave encouraging results in terms of the median OS (14.8 months) and the objective response rate (ORR) $(39 \%) .{ }^{69}$

The study NCT00570713 ${ }^{70}$ was a Phase II, double-blind, randomized controlled trial, in which amatuximab was administered with gemcitabine in patients with unresectable PC. The patients were randomized to gemcitabine alone or gemcitabine plus amatuximab. The primary outcome was OS, and the secondary outcome measures were PFS and best ORR. The treatment arm (gemcitabine plus placebo) showed better results compared to amatuximab, for all the three main outcomes, but no statistical analysis was provided. The posted data are available at www.ClinicalTrials.gov. ${ }^{44}$

NCT0235714771 (acronym: ARTEMIS) was another Phase II clinical trial, started in 2015 with the main objective to evaluate the OS in patients with previously untreated, unresectable MPM. The standard chemotherapy regimen was administered to all the patients in combination with amatuximab or a placebo. After four or six induction cycles, the stable patients continued maintenance therapy with either amatuximab or placebo. The PFS, ORR, objective duration of response (DoR), and health-related quality of life $(\mathrm{QoL})$ were the principal secondary outcome measures. In addition, the clinical development of the drug is ongoing. Two early Phase I mono-centric studies were conducted with the objective of investigating in vivo distribution and safety of ${ }^{111}$ In radio-labeled amatuximab in MSLNexpressing cancers (NCT0152132572 and NCT01413451 $1^{73}$ ). Despite the small number of recruited patients (6 and 7, respectively), Lindenberg et $\mathrm{al}^{65}$ reported their findings that ${ }^{111}$ In-amatuximab showed a good tolerability, the dosimetry profile was favorable, and the physiologic uptake was detectable in the liver, kidneys, spleen, and heart. The uptake of ${ }^{111}$ In-amatuximab was higher in mesotheliomas compared to PCs. This study was realized with the objective of refining imaging techniques in patients with advanced cancers. ${ }^{65}$

\section{MSLN targeting: novel agents}

MSLN expression is rather limited in normal tissues, but it is highly elevated in some solid human tumors, such as malignant mesothelioma, $\mathrm{PC}, \mathrm{OC}$, and lung adenocarcinoma. This provides the rational basis to test different agents potentially targeting MSLN.

A summary of new agents undergoing clinical evaluation is presented in Table 1, including monoclonal antibodies, in the form of single agents or as ADCs, immunotoxins, vaccines, and chimeric T-cells, containing Fv fragments that recognize MSLN.

\section{SSIP}

SS1P is a recombinant anti-MSLN immunogenic toxin that is constructed by the fusion of a variable fragment of a murine anti-MSLN antibody with the pseudomonas exotoxin 38 (PE38) portion. SS1P was tested both as a single agent and in combination with chemotherapy..$^{57,69,74}$ In one early Phase II clinical trial (NCT01362790), ${ }^{75}$ SS1P was administered in combination with pentostatin and cyclophosphamide with the aim of decreasing the immunogenicity of SS1P in patients with mesothelioma, lung cancer, or PC. The primary objectives of this study were to evaluate the tolerability and safety of a regimen of pentostatin and cyclophosphamide in combination with SS1 (dsFv)PE38 and to evaluate the ORR stratified by tumor type and the formation of antibodies SS1P. The rationale was that the administration of a conditioning regimen of pentostatin plus cyclophosphamide delays the 


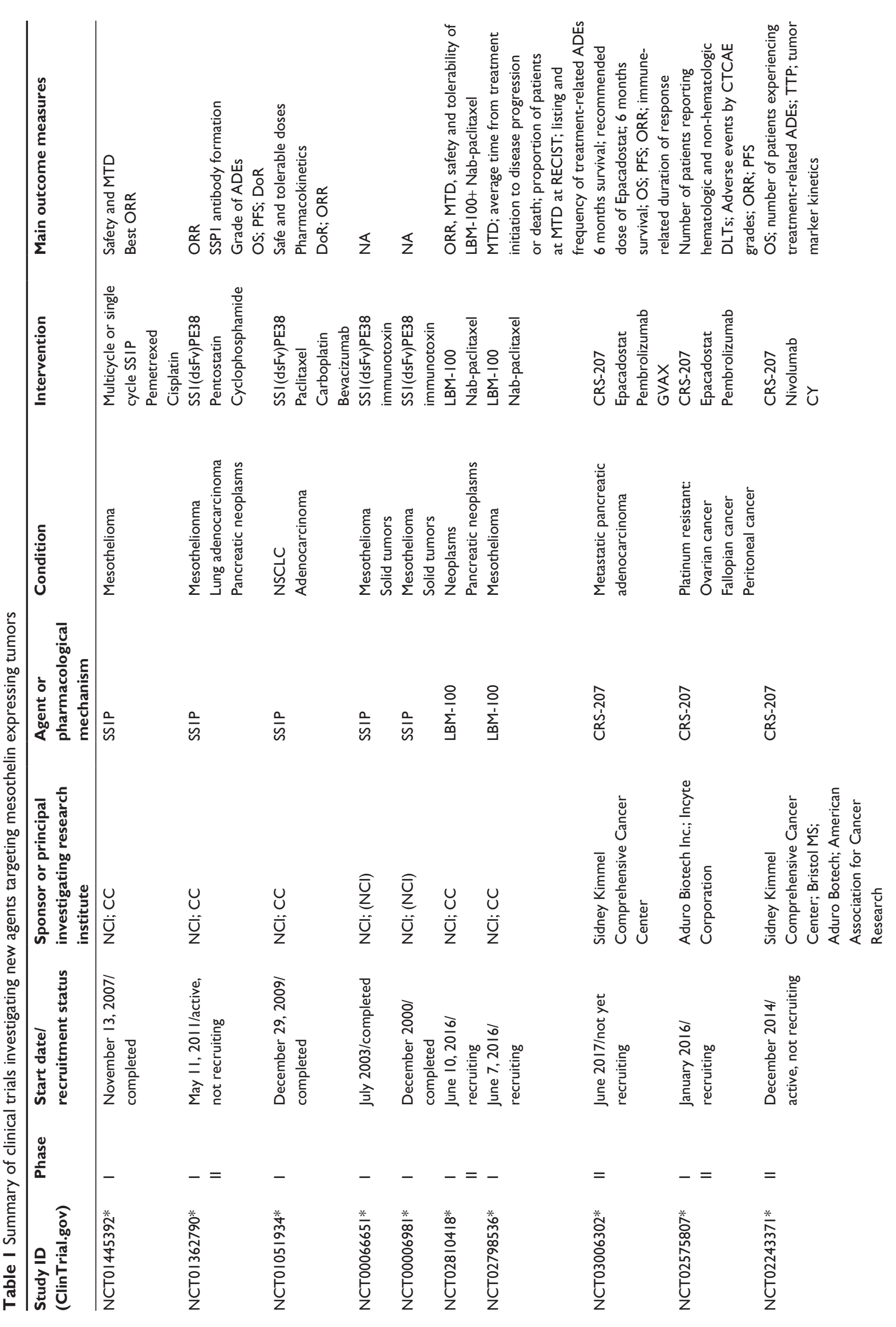




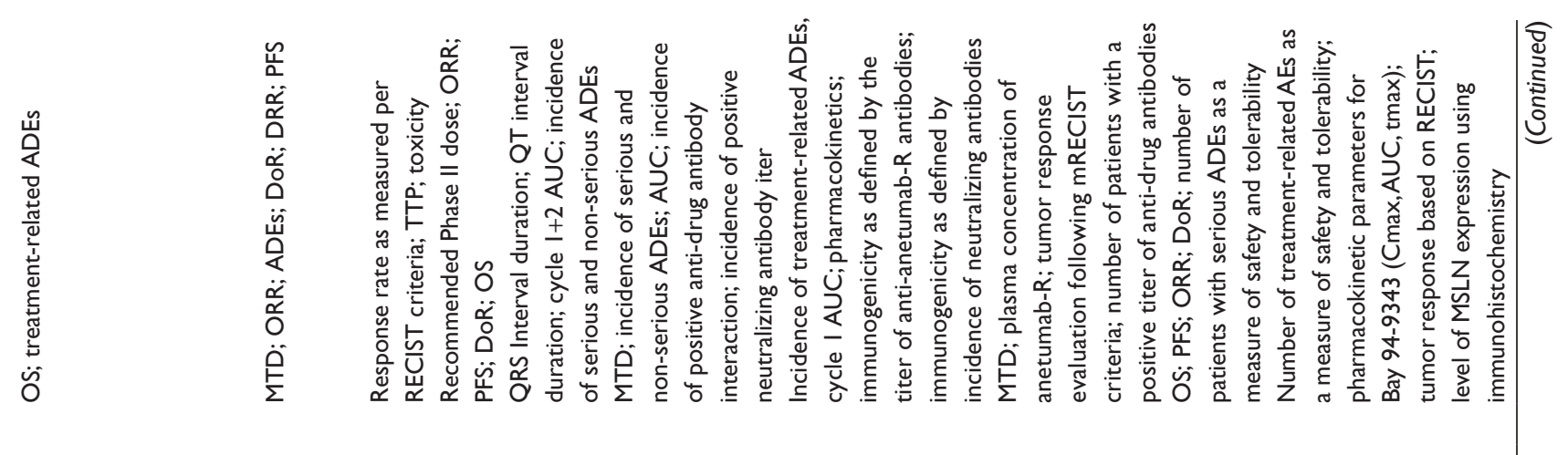

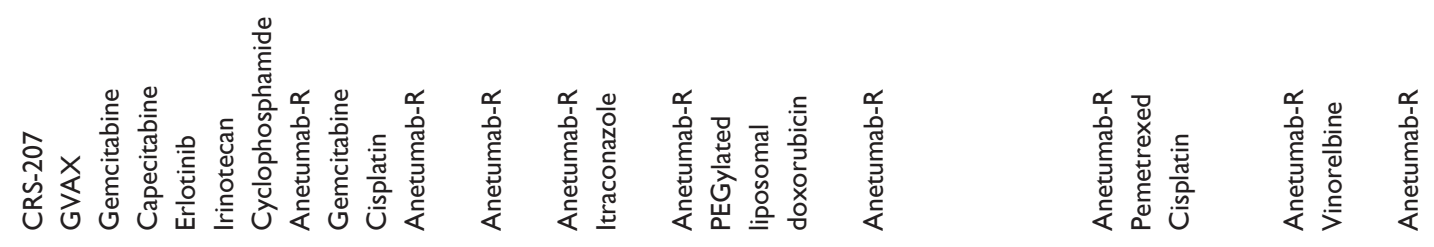
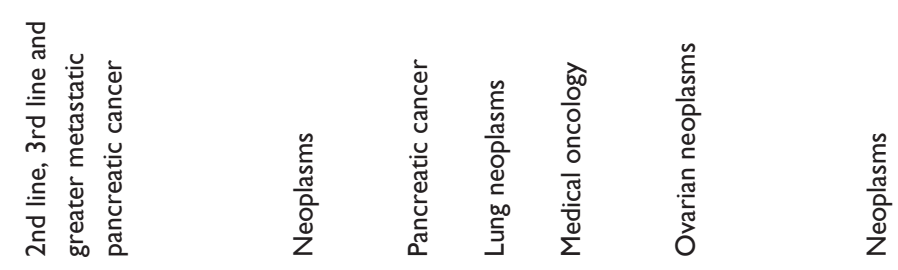

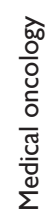

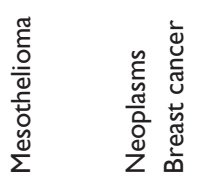

$\hat{\overbrace{}}$
ஸे
Ũ
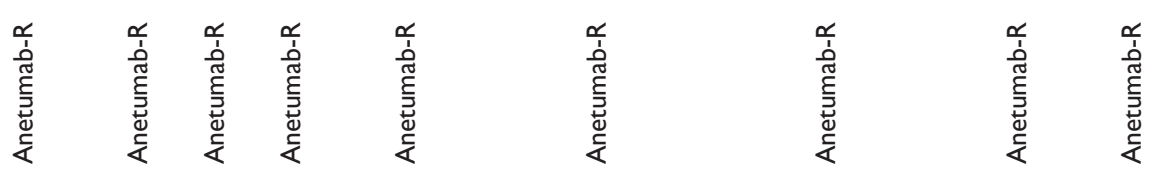

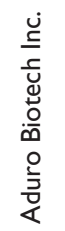
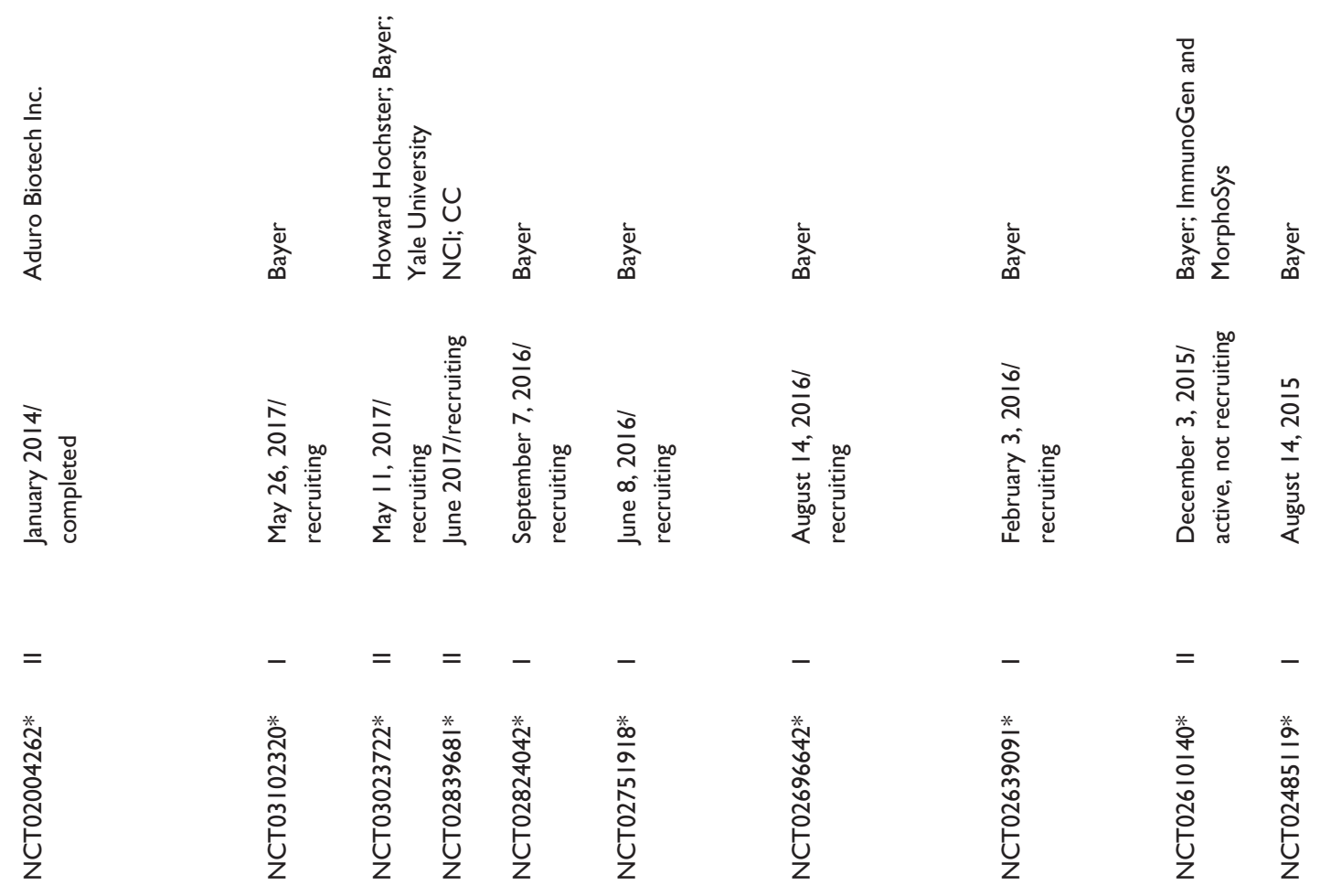


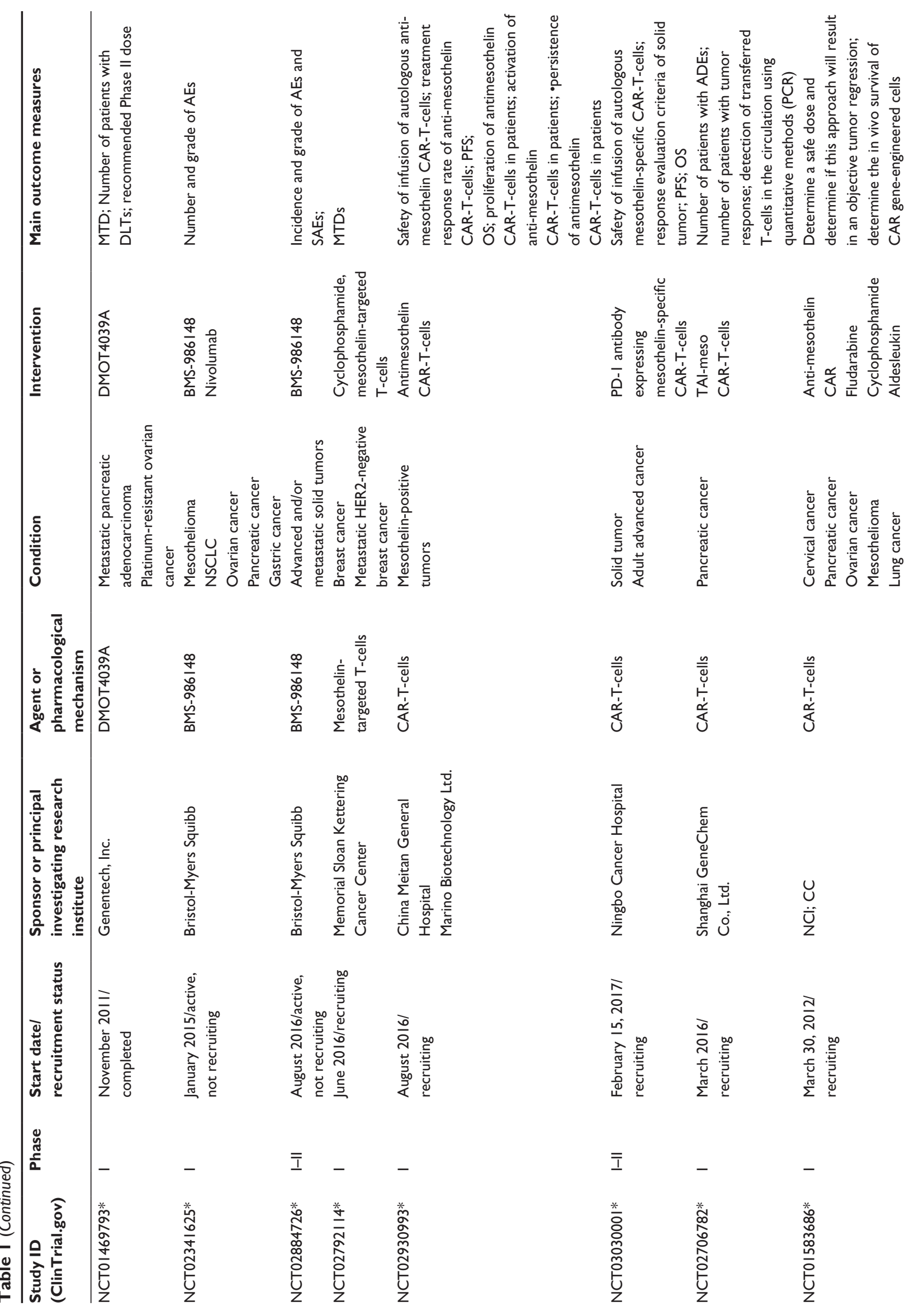



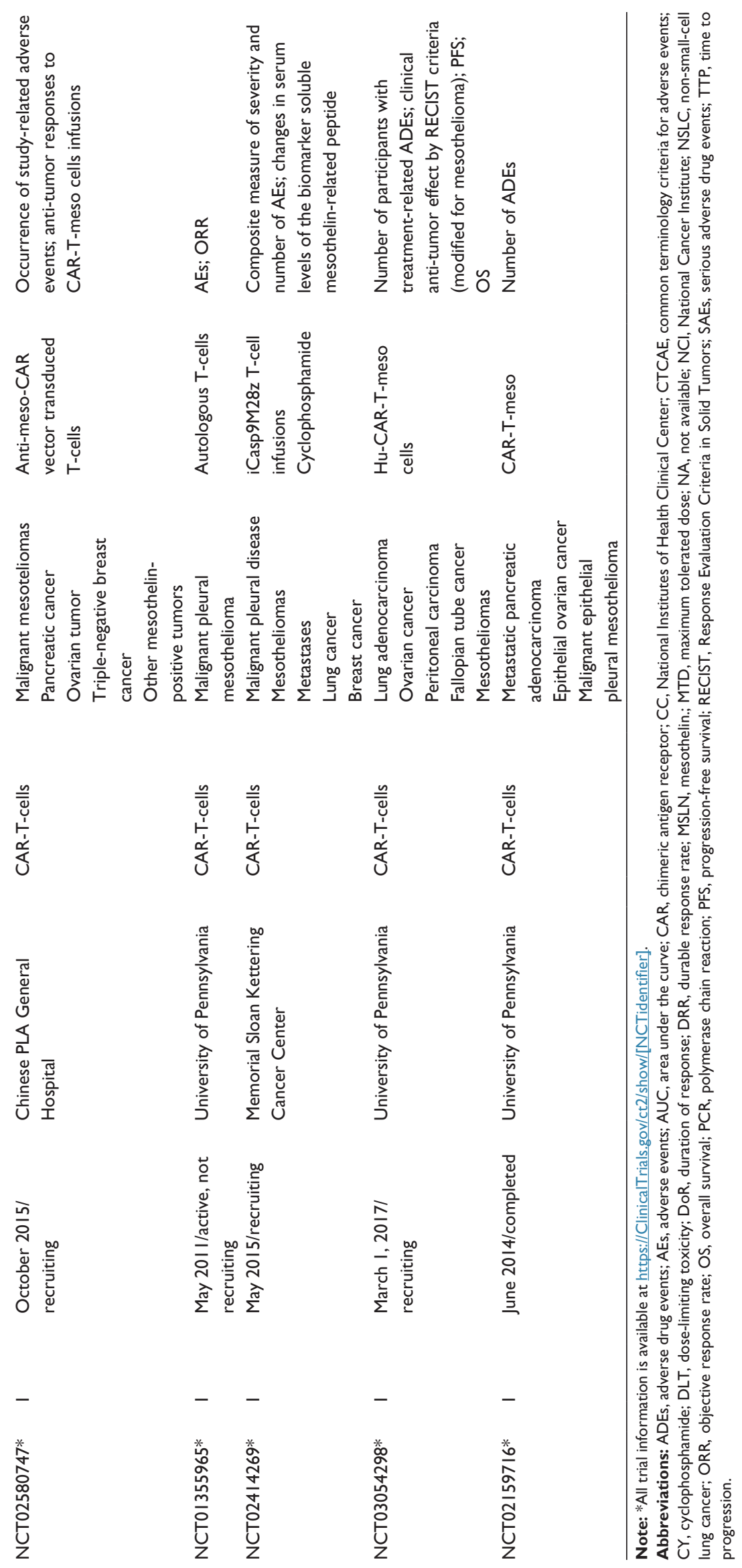


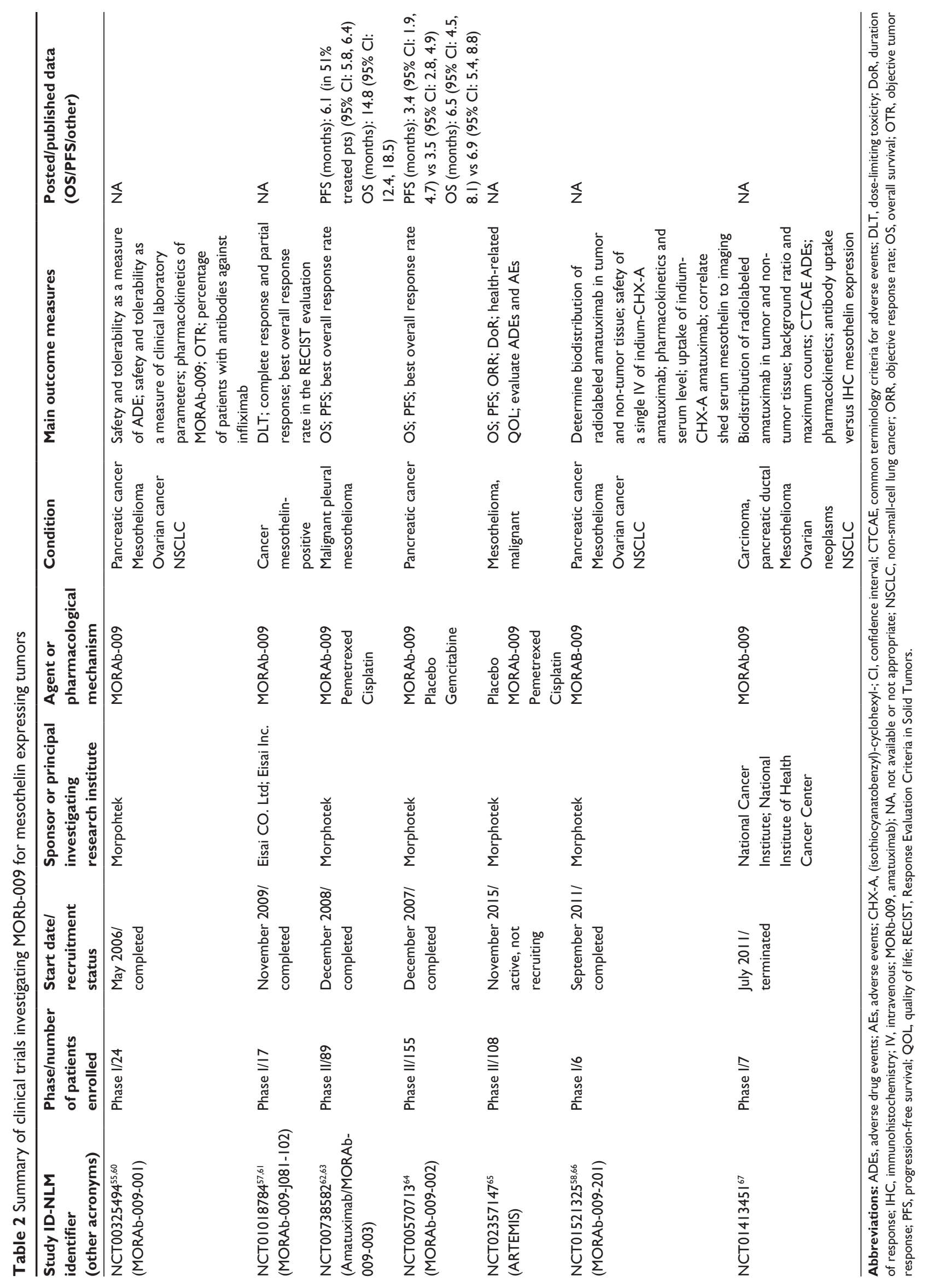


formation of anti-SS1P antibodies, allowing patients to receive multiple cycles of SS1P and, thus, potentiating the expected efficacy.

No data are actually available about a (completed) Phase I trial (NCT01051934) ${ }^{76}$ in which SS1P is administered in association with paclitaxel, carboplatin, and bevacizumab in lung adenocarcinoma.

\section{LMB- 100}

LMB-100 (previously named RG7787) is a recombinant immunogenic toxin targeting MSLN. It is based on a humanized Fab fragment with a newly engineered PE24 and is conceived to reduce the induction of immunogenicity compared to SS1P. Two initial Phase I-II studies, started in June 2016, are recruiting patients with malignant mesothelioma (NCT02798536) ${ }^{77}$ and pretreated patients with pancreatic adenocarcinoma (NCT02810418). ${ }^{78}$ Recent data published by Zhang et $\mathrm{al}^{79}$ showed that LMB-100 enhanced its activity when it was used in combination with the taxane Nab-paclitaxel in treating mesothelioma.

\section{CRS-207}

CRS-207 is a live attenuated, recombinant Listeria monocytogenes designed to express MSLN and secrete it in the cytosol of the infected antigen-presenting cells. ${ }^{80}$

It shows a synergic activity in combination with GVAX pancreas, a cell vaccine expressing human granulocyte macrophage-colony-stimulating factor and a regimen of low dose cyclophosphamide, administered to potentiate antineoplastic activity and inhibit regulatory T-cells. In a Phase II clinical trial, cyclophosphamide/GVAX and CRS-207 prolonged survival in patients with PC with a favorable toxicity. ${ }^{81}$ The same combination was investigated in pretreated patients with metastatic adenocarcinoma of the pancreas compared to chemotherapy standard regimens or to CRS-207 as a single agent (NCT02004262). ${ }^{82}$ Two other Phase II studies are active. Although they are not yet recruiting patients, they intend to combine GVAX/CRS207 with nivolumab (NCT02243371) ${ }^{83}$ or CRS-207 with epacodostat, an inhibitor of indolamine 2,3-dioxygenase (NCT03006302), ${ }^{84}$ and this study started in June 2017, with the aim of improving survival in the same setting. CRS-207 and epacadostat are also under investigation in OC (platinum-resistant), peritoneal tumor, and fallopian tumor (NCT02575807). ${ }^{85}$

The combination of CRS-207 with cyclophosphamide and standard chemotherapy was tested in a Phase I study that was completed in June 2017, which enrolled 60 patients with
MPM (NCT01675765). ${ }^{86}$ The main outcome measures are safety, the number of subjects reporting AEs, the induction of an immune response to MSLN by enzyme-linked immunosorbent spot assay, the objective tumor response and the time to progression. To date, no data have been posted about the results of this trial.

\section{BAY 94-9343}

BAY 94-9343, also called anetumab ravtansine is an antibody drug, conjugate to DM4, which is a tubulin polymerase inhibitor. Anetumab is designed to target MSLN on the cell surface and release the maytansinoid tubulin inhibitor into the cytoplasm after antibody internalization. ${ }^{87}$ In vitro, anetumab is markedly and selectively cytotoxic for MSLN overexpressing cells.

Several Phase I studies are still recruiting patients presenting different malignancies. An early Phase II study (NCT02610140), ${ }^{88}$ started in December 2015, investigated anetumab at a dose of $6.5 \mathrm{mg} / \mathrm{kg}$, administered as a monotherapy to patients with pretreated MPM compared to vinorelbine as standard therapy. The primary objective is to test the superiority of anetumab ravtansine in PFS. The secondary outcome measures include the OS, DoR, ORR, patient-reported outcomes, and number of patients reporting ADEs as a measure of safety and tolerability. The study is active but is not actually recruiting patients.

Anetumab has reached Phase II of clinical development as a single agent in PC (NCT03023722) ${ }^{89}$ and lung cancer (NCT02839681), ${ }^{90}$ and these two studies just started to recruit patients (May and June 2017, respectively). Another trial is investigating anetumab in combination with pembrolizumab for MPM (NCT03126630). ${ }^{91}$

\section{DMOT4039A}

DMOT4039A is an ADC consisting of the humanized IgG1 anti-MSLN mAb h7D9.v3 ( $\alpha$ MSLN), combined with the antimitotic agent monomethyl auristatin $\mathrm{E}$, by means of a protease-labile linker. After binding the ADC to the specific biological antigen, the complex MSLN-ADC is then internalized, and the free form is released into the cytosol, which induces $\mathrm{G}_{2} / \mathrm{M}$-phase growth arrest, cell death, and apoptosis. ${ }^{92}$ The specific antiproliferative activity in vitro and its potent antitumor activity in xenograft cancer models ${ }^{93}$ encourage researchers to test DMOT4039A in clinical trials. A multicenter, open-label, Phase I study is planned to assess the safety, tolerability, and PK of DMOT4039A in patients with unresectable $\mathrm{PC}$ or platinum-resistant $\mathrm{OC}$ (NCT01469793). ${ }^{94}$ Cohorts of participants receive escalation 
doses of DMOT4039A. A total of 54 out of the 71 enrolled patients were treated every 21 days, and MTD was assessed at $2.4 \mathrm{mg} / \mathrm{kg}$. Alternatively, in a weekly regimen, the dose was determined to be $1 \mathrm{mg} / \mathrm{kg}$. Across both the schedules, the most common toxicities were gastrointestinal symptoms. In addition, grade 3 hyperglycemia and grade 3 hypophosphatemia, at $2.8 \mathrm{mg} / \mathrm{kg}$, caused an interruption of dose escalation. A total of 6 patients ( 4 OC; 2 PC) had confirmed partial responses with DMOT4039A at $2.4-2.8 \mathrm{mg} / \mathrm{kg}$ every 21 days. ${ }^{95}$

\section{BMS-986| 48}

BMS-986148 is an anti-MSLN MAb-cytotoxic drug conjugate. No data are available about the detailed pharmacology of this agent, but it might be related to ADC MDX-1204, a MAb conjugated with the potent alkylating agent duocarmycin (MED2460). ${ }^{96}$ After cellular internalization, this agent prevents proliferation, leading to cell death and apoptosis. An initial first Phase I study planned to investigate the safety and tolerability of BMS-986148 in combination with nivolumab, with the principal aim of highlighting the most hazardous AEs and SAEs (NCT02341625). ${ }^{97}$ The secondary outcome measures consisted of the evaluation of PK parameters, immunogenicity, and a better understanding of pharmacodynamics. The anti-tumor activity was defined in terms of the ORR, DoR, PFS, and OS. This Phase I-II study should enroll a total of more than 400 patients with MM, NSCLC, OC, PC, and gastric cancer. A smaller parallel Phase I study (NCT02884726) ${ }^{98}$ started in October 2016 in a single center in Japan, with preliminary data planned by the end of 2017 , is expected to provide important information about safety and tolerability of BMS-986148 in subjects with advanced and/or metastatic solid tumors.

\section{CARs}

CARs are cited by the journal Science as one of the "breakthroughs of 2013," of bio-immunotherapy. CARs are obtained by the combination of an antigen-recognition domain on the cell surface, derived from the single-chain variable fragment ( $\mathrm{scFv}$ ) and one (in first-generation CARs) or more (in third- to fourthgeneration CARs) stimulatory domains inside the cell, which activate an immunologic response. ${ }^{100}$ The concept that led to CARs, together with adoptive T-cell processes, represents one of the main strategies applied to manipulate patient T-cells ex vivo, a process which involves removing the patient's T-cells, genetically modifying them and infusing them back into the patient. However, because the CARs are capable of recognizing the target antigen via the $\mathrm{scFv}$-binding domain, this results in T-cell activation in a major histocompatibilityindependent manner. ${ }^{101}$ The possibility to adapt the binding moiety, while retaining the principal structure, confers CARs the opportunity to recognize any type of target and, therefore, to potentially affect any type of specific-antigen-expressing cancer. CARs demonstrate promising results against hematologic malignancies and show only minor results in the treatment of solid tumors. Few data on clinical trials are published to date. A summary of the ongoing trials involving CARs for solid tumors overexpressing MSLN was recently reported by Wang et al. ${ }^{102}$

A major concern with CARs is the potential dramatic risk of toxicity, predominantly labeled "on-target/off-tumor" toxicity and as a "cytokine stench phenomenon"; 103 and probably, this is one of the reasons why clinical trials investigating CARs are proceeding at moderate speed.

\section{Discussion and future perspectives}

The only realistic weapon currently available in modern oncology is the identification of new biological targets and biomarkers, essentially specific to the single type of cancer, and an increasingly detailed understanding of their biological pathways.

Although, in recent decades, it has been possible to increase the OS or PFS in many patients, some types of cancer remain a concrete challenge for modern oncology. Important factors such as the difficulty of obtaining a precise diagnosis when the disease is still at an early stage, the aggressive nature of the disease, or a poor differentiation in the expression of biomarkers between healthy and malignant cells are critical key points that still make it difficult to manage some cancers. Mesothelioma certainly falls into this "difficult" cancer group and still requires more knowledge specifically aimed at understanding how the inflammatory processes, as in the case of asbestos, which has a very long latency period, are triggered.

Although the global use of asbestos, considered as - albeit not unique - the main cause of mesothelioma, is banned in most advanced countries since the 1980s and 1990s, the long latency prior to diagnosis of mesothelioma (up to 40 years $)^{26,104}$ suggests that the incidence peak has not yet been reached in many countries. Furthermore, a very poor prognosis after diagnosis of mesothelioma (12-24 months) makes it really urgent to implement research on how to treat mesotheliomas. Treatment options depend on the age and status of the patients and on the stage at diagnosis. Surgery is not considered sufficient without adjuvant therapy, and 
thus, several chemotherapy programs are applied, including cisplatin, the antimetabolites pemetrexed or raltitrexed, gemcitabine, vinorelbine and, optionally, a combination with antiangiogenic agents like bevacizumab. ${ }^{18,105}$

MSLN, along with other biomarkers, is one of the targets that researchers are currently focusing on for diagnosing and treating mesotheliomas. Although the role of MSLN in cancer progression is not yet completely understood, ${ }^{106}$ many drugs targeting MSLN are currently under investigation in international, multicentric clinical trials. Hassan et $\mathrm{al}^{34}{ }^{34}$ Zhao et al, ${ }^{96}$ and, recently, Mancuso and $\mathrm{Neal}^{107}$ comprehensively reviewed the main strategies for targeting MSLN in mesothelioma and other solid tumors. By reading, in parallel, the data summarized by Hassan's review ${ }^{34}$ and the results of Inaguma's original immunohistochemistry $\operatorname{research}^{53}$ (using anti-MSLN antibodies 5B2 and MN-1), it is easy to appreciate how MSLN overexpression in many solid tumors makes this target a formidable potential ground for oncology research.

In the present paper, we describe the pharmacological profile of the promising anti-MSLN agent amatuximab, along with a summary of respective clinical trials (Table 2). Furthermore, we propose emerging data about prognostic factors in some solid tumors and updates about new agents targeting MSLN that are currently being investigated and provide an updated summary of the ongoing clinical trials (on Table 1), including those started in 2016 and 2017 (Table 1).

Amatuximab, an unconjugated antibody against MSLN, has an acceptable safety profile, but when it is used as a single agent, it shows only modest results in terms of stabilizing the disease. ${ }^{57,64}$ Nevertheless, a combination of amatuximab with chemotherapy shows clinical activity with no overlapping toxicities, in Phase II trials. These findings encourage researchers to perform additional studies with different chemotherapy combinations.

Immunotoxins are also considered a promising therapeutic strategy. However, to date, the main problem in using anti-MSLN recombinant immunotoxins is immunogenicity. A Phase I study shows that almost all of the enrolled patients develop anti-toxin antibodies after treatment with SS1P in combination with pemetrexed and cisplatin. ${ }^{69}$ Among the cohorts of patients treated with PE38-RIT, only one anaphylactic reaction was detected, after the first infusion of immunotoxin. ${ }^{108}$ Although immune-mediated reactions are very frequent, usually they are not serious. Skin rashes, even severity grade 3 , are effectively treated with steroids. ${ }^{109}$ Many efforts have been made to reduce the immunological response to increase the effectiveness of the treatment, including a combination of an immune suppression therapy with pentostatin and cyclophosphamide, which demonstrated its clinical value. Several other strategies for reducing the immune response are under investigation, and they are included in actual research programs. Zhang et $\mathrm{l}^{79}$ recently showed that LMB-100, in combination with the taxane Nab-paclitaxel, in treating mesothelioma, has a synergistic activity, which could be useful in mitigating immunogenicity.

Antibodies against MSLN have a more efficient anti-tumor activity when they are conjugated with a cytotoxic molecule compared to the unconjugated drug, as demonstrated in preclinical and clinical studies. ${ }^{96} \mathrm{DM} 4$, conjugated with anetumab, performs its cytotoxic activity mainly against rapidly replicating cells, reducing systemic toxicity, and, thus, widening its therapeutic window. Like other ADCs, it shows a favorable PK profile in terms of its half-life, increasing its therapeutic exposure with a less frequent dosing and limiting immunogenicity. On the other hand, the main toxicity associated with maytansinoid is the reduction of neutrophilis, lymphocytes, reticulocytes, and platelets along with hepatotoxicity. ${ }^{110,111}$ In conclusion, MSLN is shown to be a promising target for the treatment of several types of cancer. In treating $\mathrm{BC}$, for example, MSLN may be particularly promising for the TNBC form, in which it is reported that up to $42.3 \%$ of patients show overexpression of MSLN ${ }^{47}$ In lung adenocarcinoma, MSLN, in its mature form, is detected in $55 \%$ of patients, ${ }^{50}$ and in gastric carcinomas, the detection of elevated levels of MSLN is correlated with a poor prognosis. ${ }^{55}$

Different therapeutic strategies are under investigation after obtaining promising preclinical results. The real goal will now be to enhance its efficacy, to identify patients who can achieve the best benefit, and to limit drug-related toxicities.

Recent Phase I and II clinical trials reinforced the hypothesis that MSLN is an important target for immunotherapy, and the objective is to confirm these preliminary data. At the same time, other studies should be designed to validate the utility of MSLN as a surrogate biomarker, thus making MSLN a predictor of the potential response to therapy. Serum MSLN laboratory assessment is a useful strategy for the future development of MSLN-targeted therapies, helping to select and recruit patients who can achieve the best expected benefits by this type of treatment. To date, soluble MSLN is the only tumor biomarker that has been approved by the US Food and Drug Administration for treating mesotheliomas. ${ }^{112}$ For the purpose of selecting patients with the highest chance of benefit from the treatment, another 
research arm is focusing on PET and SPECT evaluation before ADC treatment. MSLN-specific tracers for SPECT and PET have been developed recently. ${ }^{113-116}$ Molecular imaging of tumor antibody uptake might have value in the upcoming drug development by identifying patients who may benefit from ADC treatment. Lamberts et al performed an 89Zr-PET imaging study with MMOT0530A, a MSLN antibody, in conjunction with a Phase I study with the ADC DMOT4039A (NCT01832116). ${ }^{117}$ The aim of the study was to evaluate the antibody tumor uptake, the whole body distribution, and the relation between the uptake, response to treatment, and MSLN expression. ${ }^{43}$ The authors demonstrated that with (89)Zr-MMOT0530A-PET, PC and OC lesions were visualized, along with antibody distribution, and they concluded that this technique might potentially guide personalized antibody-based treatments.

Together with predictive and diagnostic innovative tools, it will be of paramount importance to identify effective ways to synergically combine therapeutic strategies. A combination of ADCs, recombinant immunotoxins (RITs), MAbs with immunotherapeutic molecules, target therapies, or standard chemotherapy, when indicated, will provide pharmacological perspectives and will constitute the basis for pipelines at pharmaceutical companies.

For this reason, in addition to the current ongoing trials, new extensive randomized trials based on the combination treatments and on extended number of patients should be planned.

\section{Disclosure}

The authors report no conflict of interest in this work.

\section{References}

1. Chang K, Pai LH, Batra JK, Pastan I, Willingham MC. Characterization of the antigen (CAK1) recognized by monoclonal antibody K1 present on ovarian cancers and normal mesothelium. Cancer Res. 1992; 52(1):181-186.

2. Chang K, Pastan I. Molecular cloning of mesothelin, a differentiation antigen present on mesothelium, mesotheliomas, and ovarian cancers. Proc Natl Acad Sci U S A. 1996;93(1):136-140.

3. Steinbach D, Onda M, Voigt A, et al. Mesothelin, a possible target for immunotherapy, is expressed in primary AML cells. Eur J Haematol. 2007; 79(4):281-286.

4. Yu L, Feng M, Kim H, et al. Mesothelin as a potential therapeutic target in human cholangiocarcinoma. J Cancer. 2010;1(1):141-149.

5. Ho M, Onda M, Wang QC, Hassan R, Pastan I, Lively MO. Mesothelin is shed from tumor cells. Cancer Epidemiol Biomarkers Prev. 2006; 15(9): 1751.

6. Ordóñez NG. What are the current best immunohistochemical markers for the diagnosis of epithelioid mesothelioma? A review and update. Hum Pathol. 2007;38(1):1-16.

7. Bernabei R, Gambassi G, Lapane K, et al. Characteristics of the SAGE database: a new resource for research on outcomes in long-term care. SAGE (Systematic Assessment of Geriatric drug use via Epidemiology) Study Group. J Gerontol A Biol Sci Med Sci. 1999;54(1):M25-M33.
8. Ordóñez NG. Application of mesothelin immunostaining in tumor diagnosis. Am J Surg Pathol. 2003;27(11):1418-1428.

9. Robinson BW, Creaney J, Lake R, et al. Mesothelin-family proteins and diagnosis of mesothelioma. Lancet. 2003;362(9396):1612-1616.

10. Rump A, Morikawa Y, Tanaka M, et al. Binding of ovarian cancer antigen CA125/MUC16 to mesothelin mediates cell adhesion. $J$ Biol Chem. 2004;279(10):9190-9198.

11. Cheng WF, Huang CY, Chang MC, et al. High mesothelin correlates with chemoresistance and poor survival in epithelial ovarian carcinoma. Br J Cancer. 2009;100(7):1144-1153.

12. Uehara N, Matsuoka Y, Tsubura A. Mesothelin promotes anchorageindependent growth and prevents anoikis via extracellular signalregulated kinase signaling pathway in human breast cancer cells. Mol Cancer Res. 2008;6(2):186-193.

13. Kaneko O, Gong L, Zhang J, et al. A binding domain on mesothelin for CA125/MUC16. J Biol Chem. 2009;284(6):3739-3749.

14. Bharadwaj U, Marin-Muller C, Li M, Chen C, Yao Q. Mesothelin confers pancreatic cancer cell resistance to TNF- $\alpha$-induced apoptosis through Akt/PI3K/NF- $\mathrm{KB}$ activation and IL-6/Mcl-1 overexpression. Mol Cancer. 2011;31(10):106.

15. Chen SH, Hung WC, Wang P, Paul C, Konstantopoulos K. Mesothelin binding to CA125/MUC16 promotes pancreatic cancer cell motility and invasion via MMP-7 activation. Sci Rep. 2013;3:1870.

16. Morello A, Sadelain M, Adusumilli PS. Mesothelin-targeted CARs: driving t cells to solid tumors. Cancer Discov. 2016;6(2):133-146.

17. Fesnak AD, June CH, Levine BL. Engineered T cells: the promise and challenges of cancer immunotherapy. Nat Rev Cancer. 2016;16(9): 566-581.

18. DeVita VT Jr, Lawrence TS, Rosemberg SA. Cancer: Principles \& Practice of Oncology. 10th ed. USA: Wolters Kluwer Health Inc.; 2015.

19. Pastan I, Hassan R. Discovery of mesothelin and exploiting it as a target for immunotherapy. Cancer Res. 2014;74(11):2907-2912.

20. Hassan R, Remaley AT, Sampson ML, et al. Detection and quantitation of serum mesothelin, a tumor marker for patients with mesothelioma and ovarian cancer. Clin Cancer Res. 2006;12(2):447-453.

21. RarecareNet: Information Network on rare Cancers [homepage on the Internet]. Brussels: Directorate for public health and risk assessment. Available from: http://www.rarecarenet.eu/rarecarenet/index.php/ cancerlist. Accessed April 18, 2017.

22. Cancer A-Z, Key-statistics - What Are the Key Statistics about Malignant Mesothelioma? [homepage on the Internet]. New York: American Cancer Society. Available from: https://www.cancer.org/ cancer/malignant-mesothelioma/about/key-statistics.html. Accessed April 28, 2017.

23. Teta MJ, Mink PJ, Lau E, Sceurman BK, Foster ED. US mesothelioma patterns 1973-2002: indicators of change and insights into background rates. Eur J Cancer Prev. 2008;17(6):525-534.

24. Global Burden of Disease Cancer Collaboration. Fitzmaurice C, Allen C, Barber RM, et al. Global, Regional, and National Cancer Incidence, Mortality, Years of Life Lost, Years Lived with Disability, and Disability-Adjusted Life-Years for 32 Cancer Groups, 1990 to 2015: A Systematic Analysis for the Global Burden of Disease Study. JAMA Oncol. 2017;3(4):524-548.

25. Yang H, Bocchetta M, Kroczynska B, et al. TNF-alpha inhibits asbestosinduced cytotoxicity via a NF-kappaB-dependent pathway, a possible mechanism for asbestos-induced oncogenesis. Proc Natl Acad Sci USA. 2006;103(27):10397-10402.

26. Magnani C1, Ferrante D, Barone-Adesi F, et al. Cancer risk after cessation of asbestos exposure: a cohort study of Italian asbestos cement workers. Occup Environ Med. 2008;65(3):164-170.

27. Goodman JE, Nascarella MA, Valberg PA. Ionizing radiation: a risk factor for mesotelioma. Cancer Causes Control. 2009;20:1237-1254.

28. Ascoli V, Romeo E, Carnovale Scalzo C, et al. Familial malignant mesotelioma: a population-based study in central Italy [1980-2012]. Cancer Epidemiol. 2014;38:273-278.

29. Novello S, Pinto C, Torri V, et al. The Third Italian Consensus Conference for Malignant Pleural Mesothelioma: State of the art and recommendations. Crit Rev Oncol Hematol. 2016;104:9-20. 
30. Chia PL, Russell PA, Scott AM, John T. Targeting the vasculature: antiangiogenic agents for malignant mesothelioma. Expert Rev Anticancer Ther. 2016;16(12):1235-1245.

31. Stahel RA, Weder W, Felley-Bosco E, et al. Searching for targets for the systemic therapy of mesothelioma. Ann Oncol. 2015;26(8): 1649-1660.

32. Katafygiotis P, Giaginis C, Patsouris E, Theocharis S. Histone deacetylase inhibitors as potential therapeutic agents for the treatment of malignant mesothelioma. Anticancer Agents Med Chem. 2013;13(3): 476-482.

33. O'Hara M, Stashwick C, Haas AR, Tanyi JL. Mesothelin as a target for chimeric antigen receptor-modified $\mathrm{T}$ cells as anticancer therapy. Immunotherapy. 2016;8(4):449-460.

34. Hassan R, Thomas A, Alewine C, Le DT, Jaffee EM, Pastan I. Mesothelin immunotherapy for cancer: ready for prime time? J Clin Oncol. 2016;34(34):4171-4179.

35. The Human Protein Atlas [home page on the Internet]. Available from: www.proteinatlas.org. Accessed June 10, 2017.

36. Argani P, Iacobuzio-Donahue C, Ryu B, et al. Mesothelin is overexpressed in the vast majority of ductal adenocarcinomas of the pancreas: identification of a new pancreatic cancer marker by serial analysis of gene expression (SAGE). Clin Cancer Res. 2001;7(12):3862-3868.

37. Hassan R, Laszik ZG, Lerner M, Raffeld M, Postier R, Brackett D. Mesothelin is overexpressed in pancreaticobiliary adenocarcinomas but not in normal pancreas and chronic pancreatitis. Am J Clin Pathol. 2005;124(6):838-845.

38. Zervos E, Agle S, Freistaedter AG, Jones GJ, Roper RL. Murine mesothelin: characterization, expression, and inhibition of tumor growth in a murine model of pancreatic cancer. J Exp Clin Cancer Res 2016;35:39.

39. Kolivas E, Rudloff M, Poruchynsky M, et al. Mesothelin-targeted immunotoxin RG7797 has synergistic anti-tumor activity when combined with taxanes. Oncotarget. 2017;8(6):9189-9199.

40. Hanaoka T, Hasegawa K, Kato T, et al. Correlation between tumor mesothelin expression and serum mesothelin in patients with epithelial ovarian carcinoma: a potential noninvasive biomarker for mesothelintargeted therapy. Mol Diagn Ther. 2017;21(2):187-198.

41. van Scheltinga A, Ogasawara A, Pacheco G, et al. Preclinical efficacy of antibody-drug conjugate targeting mesothelin correlates with quantitative ${ }^{89} \mathrm{Zr}$-immunoPET. Mol Cancer Ther. 2017;16(1):134-142.

42. Kobayashi K, Sasaki T, Takenaka F, et al. A novel PET imaging using ${ }^{64} \mathrm{Cu}$-labeled monoclonal antibody against mesothelin commonly expressed on cancer cells. J Immunol Res. 2015;2015:268172.

43. Lamberts LE, Menke-van der Houven van Oordt CW, ter Weele EJ, et al. ImmunoPET with anti-mesothelin antibody in patients with pancreatic and ovarian cancer before anti-mesothelin antibody-drug conjugate treatment. Clin Cancer Res. 2016;22(7):1642-1652.

44. Clinicaltrials.gov [homepage on the Internet]. Registry and results database of publicly and privately supported clinical studies of human participants conducted around the world. Available from: http://www. clinicaltrials.gov/. Accessed August 10, 2017.

45. Li RY, Xian RR, Ziober A, et al. Mesothelin expression is associated with poor outcomes in breast cancer. Breast Cancer Res Treat. 2014;147(3):675-684.

46. Bayoglu IV, Kucukzeybek BB, Kucukzeybek Y, et al. Prognostic value of mesothelin expression in patients with triple negative and HER2-positive breast cancers. Biomed Pharmacother. 2015;70: 190-195.

47. Parinyanitikul N, Blumenschein GR, Wu Y, et al. Mesothelin expression and survival outcomes in triple receptor negative breast cancer. Clinical Breast Cancer. 2013;13(5):378-384.

48. Ordonez NG. Application of mesothelin immunostaining in tumor diagnosis. Am J Surg Pathol. 2003;27(11):1418-1428.

49. Miettinen M, Sarlomo-Rikala M. Expression of calretinin, thrombomodulin, keratin 5, and mesothelin in lung carcinomas of different types: an immunohistochemical analysis of 596 tumors in comparison with epithelioid mesotheliomas of the pleura. Am J Surg Pathol. 2003; 27(2):150-158.
50. Ho M, Bera TK, Willingham MC, et al. Mesothelin expression in human lung cancer. Clin Cancer Res. 2007;13(5):1571-1575.

51. Mahlon DJ, Fran V, O'Connel MJ. Mesothelin expression in the leptomeninges and meningiomas. J Histochem Cytochem. 2008;56(6): 579-585.

52. Thomas A, Chen Y, Berman A, et al. Expression of mesothelin in thymic carcinoma and its potential therapeutic significance. Lung Cancer. 2016;101:104-110.

53. Inaguma $\mathrm{S}$, wang $\mathrm{Z}$, lasota $\mathrm{J}$, et al. Comprehensive immunohistochemical study of mesothelin (MSLN) using different monoclonal antibodies 5B2 and MN-1 in 1562 tumors with evaluation of its prognostic value in malignant pleural mesothelioma. Oncotarget. 2017; 8(16):26744-26754.

54. Tomoaki I, Kazunori K, Masaaki A, et al. ERC/mesothelin is espresse in human gastric cancer tissues and cell lines. Oncol Rep. 2014; 31(1):27-33.

55. Han SH, Joo M, Kim H, Chang S. Mesothelin expression in gastric adenocarcinoma and its relation to clinical outcomes. J Pathol Transl Med. 2017;51(2):122-128.

56. Chowdhury PS, Viner JL, Beers R, Pastan I. Isolation of a high-affinity stable single-chain Fv specific for mesothelin from DNA-immunized mice by phage display and construction of a recombinant immunotoxin with anti-tumor activity. Proc Natl Acad Sci U S A. 1998;95: 669-674.

57. Hassan R, Ebel W, Routhier EL, et al. Preclinical evaluation of MORAb009, a chimeric antibody targeting tumor-associated mesothelin. Cancer Immun. 2007;19:7-20.

58. Muminova ZE, Strong TV, Shaw DR. Characterization of human mesothelin transcripts in ovarian and pancreatic cancer. BMC Cancer. 2004;12:4-19.

59. Moreno M, Mol BM, von Mensdorff-Pouilly S, et al. Toll-like receptor agonists and invariant natural killer T-cells enhance antibodydependent cell-mediated cytotoxicity (ADCC). Cancer Lett. 2008; 272(1):70-76.

60. Feng Y, Xiao X, Zhu Z, et al. A novel human monoclonal antibody that binds with high affinity to mesothelin-expressing cells and kills them by ADCC. Mol Cancer Ther. 2009;8(5):1113-1118.

61. Gubbels J, Belisle J, Onda M, et al. Mesothelin-MUC16 binding is a high affinity, $\mathrm{N}$-glycan dependent interaction that facilitates peritoneal metastasis of ovarian tumors. Mol Cancer. 2006;5:50.

62. Hassan R, Cohen SJ, Phillips M, et al. Phase I clinical trial of the chimeric anti-mesothelin monoclonal antibody MORAb-009 in patients with mesothelin-expressing cancers. Clin Cancer Res. 2010;16(24): 6132-6138.

63. Gupta A, Hussein Z, Hassan R, Wustner J, Maltzman JD, Wallin BA. Population pharmacokinetics and exposure-response relationship of amatuximab, an anti-mesothelin monoclonal antibody, in patients with malignant pleural mesothelioma and its application in dose selection. Cancer Chemother Pharmacol. 2016;77(4):733-743.

64. Fujisaka Y, Kurata T, Tanaka K, et al. Phase I study of amatuximab, a novel monoclonal antibody to mesothelin, in Japanese patients with advanced solid tumors. Invest New Drugs. 2015;33(2):380-388.

65. Lindenberg L, Thomas A, Adler S, et al. Safety and biodistribution of ${ }^{111}$ In-amatuximab in patients with mesothelin expressing cancers using Single Photon Emission Computed Tomography-Computed Tomography (SPECT-CT) imaging. Oncotarget. 2015;6(6):4496-4504.

66. Morphotek. A study of MORAb-009 in subjects with pancreatic cancer, mesothelioma, or certain types of ovarian or lung cancer. Available from: https:/clinicaltrials.gov/ct2/show/NCT00325494. NLM identifier: NCT00325494. Accessed May 24, 2017.

67. Eisai Co. Ltd., Eisai Inc. A study of MORAb-009 in patients with solid tumors. Available from: https://clinicaltrials.gov/ct2/show/ NCT01018784. NLM identifier: NCT01018784. Accessed May $24,2017$.

68. Morphotek. An efficacy study of MORAb-009 (amatuximab) in subjects with pleural mesothelioma. Available from: https://clinicaltrials.gov/ ct2/show/NCT00738582. NLM Identifier: NCT00738582. Accessed May 24, 2017 
69. Hassan R, Kindler HL, Jahan T, et al. Phase II clinical trial of amatuximab, a chimeric antimesothelin antibody with pemetrexed and cisplatin in advanced unresectable pleural mesothelioma. Clin Cancer Res. 2014;20(23):5927-5936.

70. Morphotek. An efficacy study of MORAb-009 in subjects with pancreatic cancer. Available from: https://clinicaltrials.gov/ct2/show/ NCT00570713. NLM identifier: NCT00570713. Accessed May 24, 2017.

71. Morphotek. Study of the safety and efficacy of amatuximab in combination with pemetrexed and cisplatin in subjects with unresectable malignant pleural mesothelioma (MPM). Available from: https://clinicaltrials.gov/ct2/show/NCT02357147. NLM identifier: NCT02357147. Accessed May 24, 2017.

72. Morphotek. A single-dose pilot study of radiolabeled amatuximab (MORAb-009) in mesothelin over-expressing cancers. Available from: https:/clinicaltrials.gov/ct2/show/NCT01521325. NLM identifier: NCT01521325. Accessed May 24, 2017.

73. National Cancer Institute (NCI); National Institutes of Health Clinical Center (CC). Amatuximab for high mesothelin cancers. Available from: https:/clinicaltrials.gov/ct2/show/NCT01413451. NLM identifier: NCT01413451. Accessed May 24, 2017.

74. Kreitman RJ, Hassan R, Fitzgerald DJ, Pastan I. Phase 1 trial of continuous infusion anti-mesothelin recombinant immunotoxin SS1P. Clin Cancer Res. 2009;15:5274-5279.

75. National Cancer Institute (NCI); National Institutes of Health Clinical Center (CC). SS1P and pentostatin plus cyclophosphamide for mesothelioma. Available from: https://clinicaltrials.gov/ct2/show/ NCT01362790. NLM identifier: NCT01362790. Accessed June $6,2017$.

76. National Cancer Institute (NCI); National Institutes of Health Clinical Center (CC). A phase I trial of SS1 (dsFv) PE38 with paclitaxel, carboplatin, and bevacizumab in subjects with unresectable non-small cell lung adenocarcinoma. Available from: https://clinicaltrials.gov/ ct2/show/NCT01051934. NLM identifier: NCT01051934. Accessed June 6, 2017.

77. National Cancer Institute (NCI); National Institutes of Health Clinical Center (CC). Mesothelin-targeted immunotoxin LMB-100 in people with malignant mesothelioma. Available from: https://clinicaltrials.gov/ ct2/show/NCT02798536. NLM identifier: NCT02798536. Accessed June 6, 2017.

78. National Cancer Institute (NCI); National Institutes of Health Clinical Center (CC). Mesothelin-targeted immunotoxin LMB-100 alone or in combination with nab-paclitaxel in people with previously treated metastatic and/or locally advanced pancreatic ductal adenocarcinoma and mesothelin expressing solid tumors. Available from: https://clinicaltrials.gov/ct2/show/NCT02810418. NLM identifier: NCT02810418. Accessed June 6, 2017.

79. Zhang J, Khanna S, Jiang Q, et al. Efficacy of anti-mesothelin Immunotoxin RG7787 plus Nab-Paclitaxel against mesothelioma patientderived xenografts and mesothelin as a biomarker of tumor response. Clin Cancer Res. 2017;23(6):1564-1574.

80. Brockstedt DG, Giedlin MA, Leong ML, et al. Listeria-based cancer vaccines that segregate immunogenicity from toxicity. Proc Natl Acad Sci US A. 2004;101:13832-13837.

81. Le DT, Wang-Gillam A, Picozzi V, et al. Safety and survival with GVAX pancreas prime and listeria monocytogenes-expressing mesothelin (CRS-207) boost vaccines for metastatic pancreatic cancer. J Clin Oncol. 2015;33:1325-1333.

82. Aduro Biotech, Inc. Safety and efficacy of combination listeria/GVAX pancreas vaccine in the pancreatic cancer setting. Available from: https:/clinicaltrials.gov/ct2/show/NCT02004262. NLM identifier: NCT02004262. Accessed June 6, 2017.

83. Sidney Kimmel Comprehensive Cancer Center; Bristol-Myers Squibb; Stand Up to Cancer; Aduro BioTech; American Association for Cancer Research. GVAX pancreas vaccine (with CY) and CRS-207 with or without nivolumab. Available from: https:/clinicaltrials.gov/ ct2/show/NCT02243371. NLM identifier: NCT02243371. Accessed June 10, 2017.
84. Sidney Kimmel Comprehensive Cancer Center. Epacadostat, pembrolizumab, and CRS-207, with or without CY/GVAX pancreas in patients with metastatic pancreas cancer. Available from: https://clinicaltrials. gov/ct2/show/NCT03006302. NLM identifier: NCT03006302. Accessed June 10, 2017.

85. Aduro Biotech, Inc.; Incyte Corporation. Safety and efficacy of CRS-207 with epacadostat in platinum resistant ovarian, fallopian or peritoneal cancer. Available from: https://clinicaltrials.gov/ct2/ show/NCT02575807. NLM identifier: NCT02575807. Accessed June 10, 2017.

86. Aduro Biotech, Inc. Safety and efficacy of listeria in combination with chemotherapy as front-line treatment for malignant pleural mesothelioma. Available from: https://clinicaltrials.gov/ct2/show/ NCT01675765. NLM identifier: NCT01675765. Accessed June $10,2017$.

87. Golfier S, Kopitz C, Kahnert A, et al. Anetumab ratvansine: a novel mesothelin-targeting antibody-drug conjugate cures tumors with heterogeneous target expression favored by bystander effect. $\mathrm{Mol}$ Cancer Ther. 2014;13(6):1537-1548.

88. Bayer-Immunogen and MorphoSys. Phase II anetumab ratvansine as 2nd line treatment for malignant pleural mesothelioma (MPM). Available from: https://clinicaltrials.gov/ct2/show/NCT2610140. NLM identifier: NCT02610140. Accessed August 14, 2017.

89. Howard Hochster; Bayer; Yale University. Phase II anetumab ravtansine in pre-treated mesothelin-expressing pancreatic cancer. Available from: https://clinicaltrials.gov/ct2/show/NCT03023722. NLM identifier: NCT03023722. Accessed June 10, 2017.

90. National Cancer Institute (NCI); National Institutes of Health Clinical Center (CC). Anti-mesothelin antibody drug conjugate anetumab ravtansine for mesothelin expressing lung adenocarcinoma. Available from: https:/clinicaltrials.gov/ct2/show/NCT02839681. NLM identifier: NCT02839681. Accessed June 10, 2017.

91. National Cancer Institute (NCI). Pembrolizumab with or without anetumab ravtansine in treating patients with mesothelin-positive pleural mesothelioma. Available from: https://clinicaltrials.gov/ct2/ show/NCT03126630. NLM identifier: NCT03126630. Accessed June 10, 2017.

92. Francisco JA, Cerveny CG, Meyer DL, et al. cAC10-vcMMAE, an anti CD30 monomethyl auristatin E conjugate with potent and selective antitumor activity. Blood. 2003;102:1458-1465.

93. Scales SJ, Gupta N, Pacheco G, et al. An antimesothelin-monomethyl auristatin e conjugate with potent antitumor activity in ovarian, pancreatic, and mesothelioma models. Mol Cancer Ther. 2014;13: 2630-2640.

94. Genentech, Inc. A study of DMOT4039A in participants with unresectable pancreatic or platinum-resistant ovarian cancer. Available from: https:/clinicaltrials.gov/ct2/show/NCT01469793. NLM identifier: NCT001469793. Accessed July 27, 2017.

95. Weekes CD, Lamberts LE, Borad MJ, et al. Phase I study of DMOT4039A, an antibody-drug conjugate targeting mesothelin, in patients with unresectable pancreatic or platinum-resistant ovarian cancer. Mol Cancer Ther. 2016;15(3):439-447.

96. Zhao XY, Subramanyam B, Sarapa N, Golfier S, Dinter H. Novel antibody therapeutics targeting mesothelin in solid tumors. Clin Cancer Drugs. 2016;3(2):76-86.

97. Bristol-Myers Squibb. A study of BMS-986148 in patients with select advanced solid tumors. Available from: https://clinicaltrials.gov/ct2/ show/NCT02341625. NLM identifier: NCT02341625. Accessed July 27, 2017.

98. Bristol-Myers Squibb. Phase 1 study of mesothelin-ADC. Available from: https://clinicaltrials.gov/ct2/show/NCT02884726. NLM identifier: NCT02884726. Accessed July 27, 2017.

99. Couzin-Frankel J. Breakthrough of the year. Science. 2013;342(6165): 1432-1433.

100. Fesnak AD, June CH, Levine BL. Engineered T cells: the promise and challenges of cancer immunotherapy. Nat Rev Cancer. 2016; 16(9):566-581. 
101. Shi H, Sun M, Liu L, Wang Z. Chimeric antigen receptor for adoptive immunotherapy of cancer: latest research and future prospects. Mol Cancer. 2014;13:219.

102. Wang Z, Guo Y, Han W. Current status and perspectives of chimeric antigen receptor modified T cells for cancer treatment. Protein Cell. 2017 Epub May 2.

103. Sadelain M. CAR therapy: the CD19 paradigm. J Clin Invest. 2015; 125(9):3392-3400.

104. Sun H, Vaynblat A, Pass HI. Diagnosis and prognosis - review of biomarkers for mesothelioma. Ann Transl Med. 2017;5(11):244.

105. Levin PA, Dowell JE. Spotlight on bevacizumab and its potential in the treatment of malignant pleural mesothelioma: the evidence to date. Onco Targets Ther. 2017;10:2057-2066.

106. Tang Z, Qian M, Ho M. The role of mesothelin in tumor progression and targeted therapy. Anticancer Agents Med Chem. 2013;13(2): 276-280.

107. Mancuso M, Neal JW. Novel systemic therapy against malignant pleural mesothelioma. Transl Lung Cancer Res. 2017;6(3):295-314.

108. Kreitman RJ, Stetler-Stevenson M, Margulies I, et al. Phase II trial of recombinant immunotoxin RFB4(dsFv)-PE38 (BL22) in patients with hairy cell leukemia. J Clin Oncol. 2009;27(18):2983-2990.

109. Kreitman RJ, Hassan R, Fitzgerald DJ, Pastan I. Phase I trial of continuous infusion anti-mesothelin recombinant immunotoxin SS1P. Clin Cancer Res. 2009;15:5274-5279.

110. Poon KA, Flagella K, Beyer J, et al. Preclinical safety profile of trastuzumab emtansine (T-DM1): mechanism of action of its cytotoxic component retained with improved tolerability. Toxicol Appl Pharmacol. 2013;273(2):298-313.
111. Li D, Poon KA, Yu SF, et al. DCDT2980S, an anti-CD22-monomethyl auristatin E antibody-drug conjugate, is a potential treatment for nonHodgkin lymphoma. Mol Cancer Ther. 2013;12(7):1255-1265.

112. Creaney J, Robinson BWS. Malignant mesothelioma biomarkers. From discovery to use in clinical practice for diagnosis, monitoring, screening and treatment. Chest. 2017;152(1):143-149.

113. Hassan R, Wu C, Brechbiel MW, Margulies I, Kreitman RJ, Pastan I. 111 Indium-labeled monoclonal antibody K1: biodistribution study in nude mice bearing a human carcinoma xenograft expressing mesothelin. Int J Cancer. 1999;80:559-563.

114. Shin IS, Lee SM, Kim HS, et al. Effect of chelator conjugation level and injection dose on tumor and organ uptake of 111In-labeled MORAb-009, an anti-mesothelin antibody. Nucl Med Biol. 2011;38: 1119-1127.

115. Misri R, Saatchi K, Ng SS, Kumar U, Hafeli UO. Evaluation of 111 In labeled antibodies for SPECT imaging of mesothelin expressing tumors. Nucl Med Biol. 2011;38:885-896.

116. Yoshida C, Sogawa C, Tsuji AB, et al. Development of positron emission tomography imaging by $64 \mathrm{Cu}$-labeled fab for detecting $\mathrm{ERC} /$ mesothelin in a mesothelioma mouse model. Nucl Med Commun. 2010; 31:380-388.

117. University Medical Center Groningen. 89Zr-MMOT PET imaging in pancreatic and ovarian cancer patients (MMOT). Available from: https://clinicaltrials.gov/ct2/show/NCT01832116. NLM identifier: NCT01832116. Accessed July 31, 2017.
OncoTargets and Therapy

\section{Publish your work in this journal}

OncoTargets and Therapy is an international, peer-reviewed, open access journal focusing on the pathological basis of all cancers, potential targets for therapy and treatment protocols employed to improve the management of cancer patients. The journal also focuses on the impact of management programs and new therapeutic agents and protocols on

\section{Dovepress}

patient perspectives such as quality of life, adherence and satisfaction. The manuscript management system is completely online and includes a very quick and fair peer-review system, which is all easy to use. Visit http://www.dovepress.com/testimonials.php to read real quotes from published authors. 